\title{
Treating verbal short-term memory deficits by increasing the duration of temporary phonological representations: A case study
}

\author{
S. Majerus ${ }^{\mathrm{a}, \mathrm{b}}$, M.-A. van der Kaa ${ }^{\mathrm{c}}$, C. Renard ${ }^{\mathrm{d}}$, M. Van der Linden $^{\mathrm{a}, \mathrm{e}}$, M. Poncelet ${ }^{\mathrm{a}}$ \\ a Department of Cognitive Sciences, University of Liège, Belgium \\ ${ }^{\mathrm{b}}$ Belgian National Fund for Scientific Research (FNRS), Belgium \\ ${ }^{\mathrm{c}}$ Neuropsychological Rehabilitation Unit, University Hospital of Liège, Belgium \\ ${ }^{\mathrm{d}}$ Department of Speech and Language Pathology, University Hospital of Liège, Belgium \\ ${ }^{\mathrm{e}}$ Cognitive Psychopathology Unit, University of Geneva, Geneva, Switzerland
}

\section{Introduction}

Rehabilitation of verbal short-term memory (vSTM) deficits in aphasic patients has been the focus of very few studies, despite the fact that their incidence in aphasia is high and that they further handicap residual language functioning. The few existing treatment studies on vSTM deficits have shown mitigated results and targeted attentional/ executive aspects of working memory rather than passive short-term storage capacity.

We report a rehabilitation procedure that addresses more directly limitations in passive storage capacity for phonological information. Our procedure, based on short-term delayed repetition of meaningful and meaningless phonological information, is supposed to enhance short-term storage capacity by restoring more stable and longer lasting temporary activation of phonological representations. This procedure is inspired by the interactive spreading activation model, which relates VSTM deficits to pathologically increased decay rates of temporarily activated phonological representations (Martin, Saffran, \& Dell, 1996).

\section{Case description}

BJ, a 50-year-old designer, suffered from a stroke in 1997. A CT scan evidenced a focal left-sided lesion including the posterior part of the superior temporal gyrus and adjacent parietal cortex. She initially presented difficulties in both single word comprehension and production, which evolved favorably as a result of speechlanguage therapy. In 1999, she consulted our unit for persistent difficulties in retaining digit sequences, in mental calculation, and in speech comprehension in multi-talker situations. Her speech was fluent. A standardized language assessment showed normal word naming and word/sentence comprehension abilities. Single nonword repetition was poor, especially for long nonwords (accuracy: .45 and .86 for long and short nonwords, respectively). Minimal pair discrimination for nonsense syllables differing by a single consonant or vowel (e.g. [bada]; [bebi]) was relatively preserved, although performance for consonant oppositions ranged at the lower end of control performance (.86 and .85, for consonants and vowels, respectively; control range: .85-1.00 and .801.00). Digit and word span did not exceed 3 items, and nonword span was below 2.

Complementary testing determined whether this performance profile was due to vSTM limitations or to additional subtle speech perception deficits. A first task assessed minimal pair discrimination for nonword syllables presented at accelerated speech rates (using speech editing software), resulting in greater demands for temporal acoustic analysis. Her performance remained in the normal range for both consonant and vowel oppositions (.71 and .82; control range: .61-.95 and .65-.95).

Speech comprehension was further examined using an auditory lexical decision task, each target word being preceded by a semantically related prime word or a phonologically related prime word. BJ showed normal accuracy (.92; control range: .89-1.00), a large semantic priming effect (217 ms; control range: $23-232 \mathrm{~ms})$ but no phonological priming effect (4 ms; control range: $35-102 \mathrm{~ms}$ ). The high accuracy and semantic priming effects suggest that BJ correctly accesses phonological and lexico-semantic representations from speech input and that semantic activation is maintained over time. At the same time, the absence of phonological priming effects suggests that initial phonological activation exerts no influence on subsequent phonological activations, possibly due to excessive decay of the initial phonological activation. This is also supported by BJ's performance on a set of word and nonword repetition and rhyme judgment tasks. Her performance was extremely poor in repetition and rhyme judgment tasks when using nonwords but performance was normal for word stimuli whose temporary storage benefits from activation of underlying lexico-semantic representations (see Table 1 - pretherapy assessment). In sum, the cognitive analysis of BJ confirms a severe deficit in short-term maintenance of phonological information. 
Table 1: A selection of tests presented to BJ before and after therapy

\begin{tabular}{|c|c|c|c|c|}
\hline & $\begin{array}{l}\text { Initial assessments } \\
(1997+1999)\end{array}$ & $\begin{array}{l}\text { Pre-therapy } \\
\text { (2001) }\end{array}$ & $\begin{array}{l}\text { Post-therapy } \\
(2003)\end{array}$ & Significance pre- vs. post-therapy \\
\hline Digit span & 3 & 3 & 5 & Within normal limits after therapy \\
\hline Word span & 3 & 3 & 3 & Unchanged after therapy \\
\hline Proportion of words recalled & $\mathrm{na}^{\mathrm{a}}$ & .43 & .72 & $\chi^{2}(1)=27.14, p<.001$ \\
\hline Nonword span & $<2$ & $<2$ & 3 & Within normal limits after therapy \\
\hline $\begin{array}{l}\text { Proportion of nonwords } \\
\text { recalled }\end{array}$ & .00 & .00 & .38 & $\chi^{2}(1)=46.91, p<.001$ \\
\hline \multicolumn{5}{|l|}{ Single word repetition } \\
\hline High frequency & & .96 & .98 & n.s. \\
\hline Low frequency & & .86 & .92 & n.s. \\
\hline \multicolumn{5}{|l|}{ Single nonword repetition } \\
\hline High phonotactic frequency & & .22 & .48 & $\chi^{2}(1)=14.86, p<.001$ \\
\hline Low phonotactic frequency & & .23 & .30 & n.s. \\
\hline \multicolumn{5}{|l|}{ Rhyme judgment } \\
\hline Words & & 1.00 & .99 & n.s. \\
\hline Nonwords & & .75 & .95 & $\chi^{2}(1)=15.69, p<.001$ \\
\hline \multicolumn{5}{|l|}{ Minimal pair discrimination } \\
\hline Consonant oppositions & .86 & .86 & .88 & n.s. \\
\hline Vowel oppositions & .85 & .93 & .89 & n.s. \\
\hline
\end{tabular}

${ }^{\text {a }}$ No proportions of words recalled are reported as task administration had been stopped at span length, contrary to the word span tasks administered at later time points.

\section{Rehabilitation}

Our intervention procedure aimed to stabilize activated phonological representations and to increase their activation maintenance over time. Training material consisted in over 250 pairs of bisyllabic words or nonwords (e.g., bureau-sureau or $\mathrm{t} \tilde{\varepsilon} \mathrm{va}-\mathrm{t} \tilde{\varepsilon} \int \mathrm{a}$ ) differing by a single consonant. The first treatment phase was intended to stabilize initial activation of the phonological representation of the target stimulus. This phase consisted in immediate repetition of the different word or nonword pairs. Immediate repetition for each pair was practiced until it was correctly reproduced on two consecutive trials. The second treatment phase was intended to increase the duration of temporary activation of phonological representations. Here, all word and nonword items were successively practiced for delayed recall, after a filled delay of $5 \mathrm{~s}$ (during which BJ had to count backwards). Delayed recall was practiced for each stimulus pair until performance was correct on two consecutive trials. For both first and second training phases, word pairs were always trained before nonword pairs were introduced. At the end of this treatment, the entire training procedure was repeated with new stimulus pairs differing this time by a single vowel.

\section{Results}

After 16 months of therapy (8 sessions/month), we observed a modest improvement for digit and nonword span, and a significant increase of number of nonwords and words correctly repeated in word or nonword span tasks (Table 1). Single nonword repetition for bisyllabic (untrained) nonwords containing phoneme patterns of high or low phonotactic probability improved, especially for high probability nonwords. Rhyme judgment for nonwords also significantly improved. After therapy, BJ reported to have much less difficulties for speech comprehension in multi-talker situations or while driving her car. These results seem to be specific to the treatment as performance in span tasks had not changed in the 4 years preceding the treatment (see Table 1), despite intensive speech-language therapy that had targeted BJ's productive language difficulties. It is also interesting to note that post-therapy performance did not change for the minimal pair discrimination task, which remained at the lower range of control performance.

\section{Discussion}

The present study demonstrates that the rehabilitation of chronic limitations in vSTM for phonological information is possible. Future studies have to replicate these results in other patients with similar deficits but should also address whether deficits in VSTM for lexico-semantic information can benefit from this type of intervention. 
Published in: Brain and Language (2005), vol.95, iss.1, pp.174-175

Status: Postprint (Author's version)

\section{Reference}

Martin, N., Saffran, E. M., \& Dell, G. S. (1996). Recovery in deep dysphasia: Evidence for a relation between auditory-verbal STM capacity and lexical errors in repetition. Brain and Language, 52, 83-113. 